\title{
Por um turismo para as comunidades locais
}

\author{
For a tourism for local communities
}

\author{
Leticia Bartoszeck Nitsche (NITSCHE, L. B.) ${ }^{*}$
}

RESUMO - Tendo em vista uma preocupação com as pequenas comunidades receptoras de turismo que não interagem com autonomia na gestão da atividade, a ideia principal do texto se sustenta na afirmação de que é necessário conhecer a constituição de uma comunidade como grupo cultural e as suas relações com o lugar para indicar caminhos pelos quais o turismo poderia ter o protagonismo dos moradores.

Palavras-chave: Turismo; Comunidade; Espaço vivido; Geografia cultural.

\begin{abstract}
Given a concern with small tourism host communities that do not interact with autonomy in the management of the activity, the main idea of the text is based on the claim that it is necessary to know the structure of a community as a cultural group and its relations with the place to indicate ways in which tourism could have the role of residents.
\end{abstract}

Key words: Tourism; Community; Lived space; Cultural geography.

\footnotetext{
* Graduação em Turismo, Especialização em Planejamento e Gestão do Turismo, Mestrado e Doutorado em Geografia pela Universidade Federal do Paraná (UFPR). Professora do Departamento de Turismo da UFPR junto ao Curso de Graduação em Turismo e ao Programa de Pós-Graduação de Mestrado em Turismo. Endereço para correspondência: Rua Desembargador Isaias Bevilaqua, 59 (ap. 203). CEP: 80430-040 - Curitiba - PR (Brasil). Membro do Conselho Científico da Revista Turismo e Sociedade desde o ano de 2009. E-mail: 1ticia@gmail.com
} 


\section{INTRODUÇÃO}

A presente reflexão tem o propósito de se somar às opiniões daqueles que se atêm às questões antropológicas, sociais e ambientais, buscando o pensar sobre a posição da sociedade e da natureza no processo de desenvolvimento turístico, sob uma perspectiva humanista.

Não se pretende aqui discordar que a atividade turística deve ser também economicamente viável, dependendo de um conjunto de infraestruturas diversas, equipamentos, instalações, serviços e gestores do processo que interajam de forma sistemática para garantir o seu funcionamento. Portanto, uma análise funcional do turismo, conforme salienta Santos Filho (2007, p. 8), apesar de proporcionar uma descrição detalhada dos fatos, enfrenta limitações lógicas como a impossibilidade de “captar a dinâmica das contradições sociais em sua referência histórica, pois só consegue captar os problemas referentes à função".

Diferentemente de uma perspectiva funcional da atividade, esse breve artigo propõe a inversão do foco de análise do 'local que deve servir ao turismo', normalmente abordado sob o ponto de vista dos 'objetos' que compõem a oferta turística, para 'o local onde, que antes de qualquer atividade turística, vivem pessoas', considerando os moradores como sujeitos.

A principal preocupação é com os projetos turísticos realizados em pequenas comunidades, onde muitas vezes a população, ao ser considerada como 'objeto' de planejamento, tende a não se envolver de forma interessada na gestão desta atividade, além de desconhecer os efeitos positivos e negativos que possam ser gerados.

O termo 'projeto turístico' aqui adotado é uma forma genérica de se referir ao conjunto de intenções e esforços existentes para que o turismo seja empreendido de forma organizada em uma localidade, mesmo que não seja representado pela descrição técnica e pormenorizada de um documento escrito.

\section{TURISMO NO ESPAÇO VIVIDO}

É necessário compreender que o espaço visitado, objeto de projetos turísticos, é o mesmo espaço também vivido por uma comunidade. Ao enxergá-lo com o olhar de 
Yi-Fu Tuan ${ }^{1}$ (1980; 1983), quando vivido, o espaço que era abstrato passa a ser tomado como Lugar (conceito) formado por uma relação de afetividade por parte das pessoas, observando-se o que o autor chama de Topofilia.

Na maioria das situações, a população não se apropria do projeto, o qual fica sob encargo do poder público, sujeito a trocas de gestão política, ou de outra instituição proponente que muitas vezes lança o projeto, mas não possui uma atuação permanente no local.

A problemática de muitos projetos turísticos em pequenas comunidades não serem assumidos pelos seus representantes pode ter várias causas. Alguns, por terem sido planejados sem considerar os reais interesses e as necessidades da comunidade, provocam uma posição de indiferença ou oposição da população, pois ela teria outras prioridades que nem sequer foram discutidas. Em outros casos, é comum que a comunidade não esteja motivada para desenvolver o projeto, pois desconhece o significado da própria atividade turística e os efeitos que ela pode gerar. Em situações mais extremas, as experiências negativas com a atividade são razão suficiente para a comunidade ser desfavorável à manutenção do turismo no local.

Em meio a estas e a tantas outras possibilidades que mantêm a população afastada dos projetos de turismo, prega-se aqui que a tentativa de encontrar soluções depende de conhecer as particularidades de cada local, sob uma perspectiva cultural.

A ideia principal deste breve artigo se sustenta na afirmativa de que é necessário conhecer a estrutura de constituição de uma comunidade e as suas relações com o lugar para indicar caminhos pelos quais o turismo poderá encontrar melhor interação e adesão nesse grupo de pessoas.

Que caminhos teóricos poderiam sustentar tal análise? Propõe-se que um deles encontre seu rumo na geografia cultural, tanto nos estudos contemporâneos sobre a cultura na formação das sociedades quanto na abordagem fenomenológica que conduz aos estudos de percepção ambiental e representações.

A geografia cultural oferece bases sólidas para a pesquisa enveredar por este caminho, em concordância com Paul Claval, que julga necessário partir dos indivíduos

\footnotetext{
${ }^{1}$ Geógrafo, nascido na China em 1930, foi professor em universidades americanas de 1956 a 1998 (TUAN, 2008). Tuan é referência para vários pesquisadores, com destaque para os seus livros 'Topofilia: um estudo da percepção e valores do meio ambiente' de 1974 (publicado em português em 1980 tradução de Lívia de Oliveira) e ‘Espaço e Lugar' de 1977 (traduzido para o português em 1983).
} 
que compõem os lugares "e de suas experiências, compreendendo o sentido que as pessoas dão à existência" (CLAVAL, 2002, p. 37).

Algumas questões podem balizar um estudo dessa natureza: Que laços fazem destas pessoas uma comunidade? Quem são os líderes da comunidade? Quais são os principais espaços de interação entre os membros do grupo? Como se manifesta a topofilia no lugar? Como os moradores percebem o turismo no seu espaço de vivência? Por que o turismo não está sendo coordenado de forma endógena na comunidade? (NITSCHE, 2012).

Nessa linha de pensamento, destaca-se a investigação do espaço vivido, como categoria de análise, o qual pode trazer resultados que auxiliem a traçar diretrizes de planejamento turístico e contribuam com uma gestão mais participativa dos atores locais.

\section{CONCLUSÕES}

Considera-se que o turismo não pode ser abordado como uma atividade isolada e desconectada da realidade local, mas deve estar inserido no contexto das discussões em voga na comunidade. Por isso, a importância de se conhecer a comunidade, segundo a visão dos seus moradores.

O projeto de turismo precisa estar integrado à dinâmica local e construído dentro da própria comunidade, não pode ser algo pronto que seja oferecido para que ela apenas cumpra com presteza as tarefas que lhe forem determinadas. Nele, a comunidade deve ter autonomia para debater o assunto tanto internamente quanto com entidades externas interessadas no turismo local. A participação de outras instituições, sem dúvida, é muito importante durante todo este processo, porém deve ser requisitado como apoio técnico e não como principal diretriz.

Um turismo que perdure e traga benefícios para uma determinada comunidade receptora depende da proatividade dos seus moradores em relação à gerência do turismo no seu espaço de vivência. Por isso a importância deflagrada de conhecer este espaço vivido, onde se enfatiza a constituição da comunidade e a sua relação com o lugar. 


\section{REFERÊNCIAS}

CLAVAL, P. A geografia cultural. 2. ed. Florianópolis: UFSC, 2001.

NITSCHE, L. B. Desvendando o espaço vivido da comunidade de Guajuvira e sua relação com o turismo, em Araucária, Paraná (PR). 223 f. Tese (Doutorado em Geografia). Setor de Ciências da Terra, Universidade Federal do Paraná (UFPR), Curitiba, 2012.

SANTOS FILHO, J. Turismo: ciência ou técnica? Revista Turismo. Disponível em <http://www.revistaturismo.com/artigos/cienciatecnica.html>. Acesso em: 24/09/2007.

TUAN, Y. F. Topofilia. São Paulo: DIFEL, 1980. 